\title{
Flu Vaccine Market In The United States: A Case Study
}

William Connell, (Email: wconnell@bryant.edu), Bryant University Sam Mirmirani, (Email: smirima@bryant.edu), Bryant University

\section{INTRODUCTION}

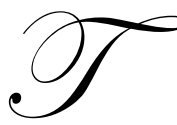

he recent experience in the United States with a shortage in available doses of flu vaccine demonstrates a heavy reliance on a limited number of suppliers for the flu vaccine. The announcement by the Centers for Disease Control and Prevention of the Department of Health and Human Services (hereinafter "Centers for Disease Control", or "CDC") in early October of 2004 that the total amount of flu vaccine prepared by a leading manufacturer at a plant in England had become contaminated and would not be available for distribution in the United States during the 2004-2005 season created an immediate shortage and challenge for the United States Department of Health and Human Services and its Centers for Disease Control and Prevention (Health and Human Services, 2004)(a). Literally overnight, federal officials were faced with the prospect of having their anticipated supply of approximately 100 million vials of injectable flu vaccine reduced by 46 to 48 million vials, with insufficient time to produce more for the imminent flu season. The reaction was reminiscent of the oil and gasoline shortages of the early 1970's, where motorists waited in long lines for gasoline pumps during the oil crisis. In 2004 reports surfaced of senior citizens waiting hours in long lines, often enduring poor conditions during such wait, in hopes of receiving one of the rare flu shots. Several states filed lawsuits against a flu vaccine distributor, essentially charging the distributor with price gouging on vials of vaccine. According to the allegations contained in these lawsuits, in some instances distributors increased prices for vials of vaccine to more than ten (10) times the market value prior to the announced shortage. (Weissman, 2004).

The timing of the flu vaccine shortage, emerging at the height of a heated presidential campaign, served as a focal point of political debate, with Democrats and Republicans blaming the other for the crisis, as well as offering differing versions of the cause and the solution for the shortage. In such debates, issues of legal liability, lack of government intervention, and insufficient profit incentives were all cited as a cause for the shortage.

Yet when one considers all the pressures on the supply side of the flu vaccine, perhaps the most surprising aspect of the 2004-2005 flu vaccine shortage was that it did not occur earlier. While anticipating potential shortages in vaccine availability, Orenstein (2002) asserts economic factors play a major role; however, when compared with other pharmaceutical products, the vaccine market has certain distinctive features that render it less attractive for a manufacturer both to enter and/or to remain in.

The purpose of this study is: (1) To investigate the cause of the flu vaccine shortage during the 2004-2005 flu season using a supply and demand analysis; (2) to discuss what problems were uncovered as a result of the shortage; and (3) to offer comment on what lessons the United States should learn from this experience.

The organization of this study is as follows. First, we provide a background on the current issues related to the flu vaccine market in the United States. In the second segment, a market assessment is given where supply and demand factors are elaborated. The third part of this study is devoted to the cost-benefit analysis of flu vaccination. Then, a set of recommendations offered which will be followed by summary and conclusions.

\section{BACKGROUND}

The Centers for Disease Control (2004)(a) defines the flu as a contagious respiratory illness caused by a form of influenza viruses. It is transmitted though respiratory droplets emitted through such actions as talking, coughing, 
and sneezing. The virus can spread from person to person through normal daily contact, especially in situations where people find themselves in close proximity to another. It can also be acquired when a person touches an item which has been contaminated by the droplets, such as a telephone, keyboard, or doorknob, and then brings the hand to the face, especially the eyes, nose, or mouth. By any objective standard, the flu is a contagious virus. Prevention remains the best way to treat the flu, and vaccination against the virus remains the most cost-effective method to prevent the flu. The vast majority of flu vaccine purchased and used in the United States is the inactivated (dead) influenza vaccine, administered through intramuscular injection. By October of 2004, approximately one hundred percent $(100 \%)$ of the injectable flu vaccines legally distributed in the United States were manufactured in Europe and came from one of two multinational corporate manufacturers, Chiron Corporation and Aventis Pasteur (Gerberding 2004).

On the eve of the 2004-2005 flu season, when health officials in the United States learned their supply of vaccine would be reduced nearly fifty percent $(50 \%)$, there was understandably concern over the lack of availability of the vaccine. This concern was particularly heightened among those classified by the CDC as being in one of the socalled "priority" or high risk groups - essentially children, elderly, health care workers, and persons with compromised immune systems.

On the simplest level, the cause of this reduction in available vaccination doses can be traced to a single incident, the contamination at a particular production site. Chiron Corporation, a California based company, manufactured its inactivated influenza vaccine, "Fluvirin," at a plant in Liverpool, England. As late as September of 2004, CDC was stating that it expected 100 million doses of flu vaccine would in the United States. Of these, approximately 46-48 million doses would come from Chiron, and the other 52 million doses would or had already come in from Aventis Pasteur (National Immunization Program 2004). Chiron's manufacturing plant in Liverpool was inspected by inspectors from Great Britain's Medicines and Healthcare Products Regulatory Agency (MHRA) on September 28-30, 2004. On October 5, 2004, MHRH issued a three month suspension of Chiron's license to manufacture the influenza vaccine at the Liverpool factory. That same day, Chiron Corporation informed the Centers for Disease Control that none of its Fluvirne vaccine would be available in the United States during the 2004-05 flu season. The entire batch - of which between 46 to 48 million doses of the influenza vaccine was to go to the United States and which the CDC counted on as part of its vaccination program -- would not be available. Thus at the start of the season, the CDC was down approximately half its expected doses for the year (Gerberding 2004).

We submit, however, that it is too simplistic to view the contamination at Chiron's facility as the sole cause of the vaccine shortage. In the fall of 2004 Aventis Pasteur (now Sanofi Pasteur), a multi-national corporation headquartered in Lyon, France, and one of the largest producers of human vaccines, was the other main supplier of injected flu vaccine to the United States (Sanofi Pasteur 2004). Its flu vaccine product, "Fluzone," distributed in the United States was manufactured in France. On October 7, 2004, Aventis Pasteur issued a press release indicating that if the company were to begin immediate production of the vaccine, it would not be ready until February or March of 2005 (Aventis Pasteur 2004). Neither Aventis nor any other enterprising pharmaceuticals manufacturer could take advantage of the market shortfall and fill the gap left by Chiron because the technology employed in flu vaccine production could not produce a vaccine quickly enough to be available for the upcoming flu season and to be profitable for the manufacturers.

\section{MARKET ANALYSIS: SUPPLY AND DEMAND ISSUES}

The production of flu vaccine involves various steps in preparation and requires a fixed period of time to complete, but which in turn must be completed in a relatively short time horizon. The predominant form of vaccination against the flu is through an injection of a vaccine which contains a killed virus. The idea behind a vaccine is to allow the body to build up an immunity to a virus. In scientific circles, a vaccine is termed a "biologic," so named because it begins as living material. The vaccine is an introduction of a dead or greatly weakened form of a virus and/or bacteria into a healthy person. The introduction of this foreign matter triggers an immune reaction from the body which the body will, if all goes well, remember when confronted at a later date with a living, more virile form of the virus or bacteria. Thus the body "learns" or develops a memory of how to defend itself (Marshall 2004). 
The vaccine is prepared using fertilized chicken eggs. These eggs must be obtained from certified farms that insure the hens are free from infection. The influenza virus is injected into the fluid surrounding the embryo. The cracked egg is resealed and the embryo is infected, with the virus developing in the egg. The virus is then extracted from the egg, killed, purified, and broken up. Only a portion of the killed virus goes into the vaccine dose. Absent production delays, the process of preparing an injectible vaccine takes from six to nine months. This, in part, answers why, by the time the damage to Chiron's vaccine does became known, it was impractical for anyone to begin new virus production for the 2004-2005 season.

Even if one were to dismiss the contamination at Chiron's plant as a one-time aberration, and not likely to be repeated, we submit that using a simple supply and demand analysis, a more fundamental problem appears in the form of substantial pressures that keep profit margins low and discourage entry into the flu vaccine production market by other manufacturers.

Maintaining inventory of flu vaccine beyond one (1) year is deemed to be inadvisable due to scientific limitations. The protection one receives from the flu vaccine is transient, and yearly injections are necessary to defend against new strains of the virus. Much of this is due to the virus itself. The flu virus mutates quickly and easily. The strains identified for one given flu season would almost certainly not be the same as those strains prevalent in the following year. Thus, researchers have a very narrow window within which to predict what the next viral strains will look like. In the United States, while it is possible to become infected at any time, flu breakouts reach epidemic levels in the winter months. The viral form that invades the United States in the fall usually is one of the three (3) strains that have ravaged the Far East and Africa, during the preceding summer months. By February of each year proceeding the flu season, researchers are trying to predict the three (3) most virulent strains of the flu which must be identified for the next flu season through research and forecasts of flu activity in Asia and Asia. These strains are collected and forwarded to laboratories which analyze them and then predict the three strains which are most likely to appear in the west during the following winter. Production must be commenced quickly to meet the 6 to 9 month window necessary to make the vaccine available by October of the same year. Assuming that the proper strains of the vaccine have been identified, the manufacturer must produce the vaccine under a tight deadline and meet rigorous standards. Thus the selection of which strains of influenza to use in the egg injection is ultimately a guess, although a heavily researched and educated one (Marshall 2004).

The manufacturer is also guessing how strong the demand for the product will be. Many vials of vaccine are destroyed every year, having never been used. If the manufacturer has made correct predictions regarding the strains, and if the process has been completed properly (a process which, as Chiron illustrates, is not a fait comple), the manufacturer seeking sales in the United States must still hope the demand among the United States population will be sufficient within the short window of opportunity for sale. While the CDC considers the flu season to run from Mid-October through April, it has been shown that the vast majority of flu vaccines will be administered in the period from October through to December. Historically, demand drops sharply with the start of the new year, although clinically benefits can be derived from taking the vaccine as late as February. It is clear that in the United States, reality dictates a limited window for the sale of the drug between October and December, even if clinical research would support a wider time frame.

There is an alternative to vaccination in the form of a nasal spray or mist. Unlike the injectabile vaccine, this intranasal version incorporates a live but attenuated or extremely weakened strain of the virus. Since the vaccine does contain a live virus (and thus exposes one to an admittedly weak strain of the flu), and is still being tested, its use to date has been limited. Generally, test trials had been completed only on healthy people between the ages of 5 and 49 years old, who have no severe immunity disease or chronic health problems. This intranasal vaccine protection accounts for only approximately $2 \%$ of the flu vaccine used in the United States, but its use may grow (Marshall, 2004). Niles (2004) states that the first intranasal vaccine, FluMist, was approved for sales in the United States in June of 2003. However, the American public has been slow to embrace this product on a wide scale, which may be due to a number of points, such as its relatively higher price in comparison to injections, that the product is frozen and requires thirty (30) minutes to thaw, and the inclusion of a still living though weakened form of the virus (Niles, 2004). To date, the intranasal spray does not represent significant competition to the injected vaccine. 
Assume arguendo that the problems at Chiron's manufacturing plant was an isolated incident. The Fluvirin vaccine was previously manufactured by Evans Vaccines, Ltd., a subsidiary of Powderjet Pharmaceuticals. Chiron acquired Powederjet, and with it Evans and the Fluvirin product, prior to the 2004 -2005 flu season. Regardless, while the contamination at the Chiron plant can be pointed to as the immediate cause of the 2004-2005 vaccine shortage, it is too simplistic to view that as the only cause. Scientific barriers primarily address why a new batch of flu vaccine could not be prepared in time once the Chiron problem was discovered. Up until 1995, flu vaccines were produced by several manufacturers in the United States. In the face of financial risk and viability, manufacturers have opted out of the market and largely relocated their production facilities overseas. This and other market factors continue to limit the entry of new manufacturers into the business of flu vaccine production.

Profitability and the lack thereof, is a driving force in a free market. For many pharmaceutical companies, the vaccine market itself is not lucrative. With low prices (flu vaccine costs (in 2004 pre-shortage) averaged $\$ 3$ to $\$ 10)$, the need to research and investigate a new vaccine each year, and the difficulty in predicting annual demand, the flu vaccine is not as profitable as other drugs (Lienwand 2004). As noted above, unlike prescription drugs, flu vaccine, has a limited life for which it is effective and is a product for which, as a practical matter, there is small window of opportunity for its sale. While this window is partly caused by the fluctuation of the composition of the virus, it is narrowed further by consumer perceptions as to both the efficacy and the need for the vaccine. In sum, Marshall et al (2004) refer to vaccines as "high-risk, high cost, low-profit products."

Demand for the flu vaccine is shaped by several factors. One of the most significant is a price ceiling imposed by the Vaccines for Children Program. The program was established under the administration of President Clinton as part of the Omnibus Reconciliation Act of 1993. Under the program, the CDC purchases vaccines from the manufacturers in bulk. The price negotiated by the CDC is almost always significantly less than what a private physician would be able to negotiate. In other words, CDC exerts monopsony power in the market. The CDC then distributes the vaccine to eligible children without charge. Eligibility includes children who are Medicaid eligible, who are without health insurance, who are underinsured and obtain vaccines through certain public health clinics, or are Native American or Alaskan natives. A private medical practice which participates in the program may receive the vaccine at no cost, for distribution to eligible children. Under federal law, the medical practice cannot charge the patient a fee for the vaccine itself, although a charge may be assessed for the office visit. Proponents of the Program point to it as a model of success, increasing the immunization rates for children, especially so among low income families. Opponents charge that the program's use of price caps essentially drove the profit margins, and thus the vaccine manufacturers, out of the United States market, to the point that in 2004 there was no domestic manufacture of injectable flu vaccine in the United States (Senacola 2004)

It seems an overstatement to suggest that the Vaccines for Children program is primarily responsible for driving down profit margins for manufacturers. The Program essentially targets certain economic and ethnic groups. Physicians must purchase vaccine for their adult patients as well as children who do not fall under the program either directly from a manufacturer or a middleman. Achieving an increase in vaccination rates among a lower income population which might not otherwise purchase the vaccine is a worthy goal. Nevertheless, through the Vaccines for Children program, the CDC does reduce the profit margin for a significant portion of the potential vaccine market. The government cannot afford to overlook the effect that this well-intentioned and largely successful program providing flu vaccines has had and continues to have on limiting profit margins and thus creating a disincentive to manufacture the vaccine beyond the orders placed by the CDC.

\section{COST-BENEFIT ANALYSIS OF FLU VACCINE INNOCULATION}

According to the CDC, during the 2003-04 season, the percentage of deaths in the United States attributed to pneumonia and influenza reached its highpoint during the weeks ending January 10-17, with $10.3 \%$ of all deaths related to the flu. The CDC termed the 2003-04 U.S. season as "moderately severe" (CDC 2005)(c). The CDC estimates that in an average year, 200,000 people in the United States require hospitalization from flu-related illness. By some estimates, approximately 36,000 people die from flu and/or flu-related illness each year (CDC 2005). Several studies have demonstrated the efficacy of vaccine use as a tool to both prevent the spread of the influenza and to minimize costs related to health care required as a result of influenza infection. This efficacy is found across 
the board, among the young, the working population, and (most especially) the elderly. Cohen (2000) studied the effect of influenza on children between the ages of 6 months and 5 years. She noted that statistically, influenza infects more children than adults, but usually without serious long-term consequences to the child. However, the infection of children has great costs not only in medical care for the child, but also because of the need for an adult parent to stay with the child during the illness. Cohen's study concluded that vaccination of preschool age children resulted in a net cost savings per vaccination for both parent and child, specifically $\$ 21.28$, in a setting where the child could be brought in by the parent/care giver and vaccinated during flexible hours (i.e. more than traditional work hours of 8:00 AM to 5:00 pm). O'Brien (2004) noted that hospitalization rates associated with influenza were the same among healthy children aged 6 to 23 months and was comparable to the hospitalization rates for higher risk groups such as the elderly. Nichol (1994) conducted a study of over 25,000 elderly patients immunized over a three (3) year period and concluded that the direct costs savings resulting from vaccination was almost five million dollars $(\$ 5,000,000)$ and averaged $\$ 117.00$ for each of the people immunized during a three year study. Bridges et al (2000) suggested that the influenza vaccine is a source of a significant amount of work absenteeism and the use of health care resources among healthy working age adults (those aged 18 to 64 years). In this study, the influenza vaccination of healthy working adults produced effective health benefits, including but not limited to the reduction of lost workdays, incidents of illness, and physician visits, when there was a good match between the strains of the virus and the vaccination. This study also suggested that the vaccination may not provide overall economic benefits in most years, questioning the conclusion from the Nichol study (1994). Bridges et al used a significantly smaller sample size than Nichol. Yet even taking Bridges et al at face value, their work suggests that the vaccine produces the lowest economic benefit when there is not a good match between the predicted strain of the virus and the actual forms that attack the populace during a flu season. This finding does not repudiate the strong economic savings suggested by the other studies listed, but instead supports increase spending in the advanced research, scouting, and prediction of the strains early in the season.

\section{RECOMMENDATIONS}

\section{Supplier Diversification}

A study of the situation with Chiron Corporation illustrates the fragile nature of a system that relies on only two (2) manufacturers for production of one hundred percent (100\%) of the United States' supply of injectable flu vaccine, and supports the need for an increase in the number of suppliers. Further, it is worth noting that despite cooperation between the CDC and Britain's MHRA, the United States is ultimately dependent upon foreign agencies to continually monitor such production and enforce appropriate health standards on a continuing basis.

The market response to the recent flu vaccine shortage is still unclear. At least one manufacturer, MedImmune, Inc., announced in December of 2004 that FluMist (Influenza Virus Vaccine Live, Intranasal) would join the list of vaccines available under the Vaccines for Children program beginning in the 2005-2006 influenza season. MedImmune purports that this would be the first live, attenuated vaccine allowed for the prevention of flu caused by influenza A and B viruses in healthy children and adolescents, age 5 to 17 to years of age. But as part of the Program, the price would still presumably be set well below a free-market price by the government, and might serve as a disincentive for other entrants into the market. ID Biomedical Corp. in Vancouver, British Columbia, GlaxcoSmithKline, and Solvey Pharmaceuticals, Inc., also announced its intent to enter the flu vaccine market in the United States, although it was not clear if or when products would be available for distribution in the United States.

\section{Removal of market impediments}

There are a number of problems or obstacles to the availability of any vaccine in the United States. According to Thaul (2003), these include production costs, liability, a weak market, and difficulty in projecting the need and/or market demand for the item. The flu vaccine arguably smashes into all in a head-on collision. As noted previously, flu vaccine production involves a considerable amount of preparation, work, and finally, luck. Based on scientific limitations, costs at the present time are generally fixed. Continued research may lead to a more streamlined process resulting in the ability to produce the vaccine at a reduced cost, resulting in economies of scale which ultimately might lead to a shorter time frame for vaccine production. But one of the lessons learned is that such 
research may not produce results quickly enough to address some of the more imminent problems raised by flu vaccine shortages.

Another market constraint, the potential liability issue, is one where the legislative process can exert some control on the market impediments. In the United States, recent sessions of congress have witnessed strong and heated debate over the issue of tort reform. Much of this debate focused on rising costs of medical malpractice insurance premiums, as well as the decline in the number of medical specialists in certain fields. Whether or not rising malpractice judgments in tort litigation are the cause of such hikes in insurance premiums, and whether caps or limitations on the amounts of judgment available under these awards, has been argued vehemently by both sides. Republican legislators in 2003 introduced a strongly fought attempt at a comprehensive cap limit on most tortuous injury for medical malpractice cases which passed the House, but failed to pass the Senate. But if passed, the effectiveness of these measures is far from certain. Hillman (2003), writing for the Congressional Research Service, summarizes that whether there is a direct causal relationship between increased liability awards and malpractice premiums in the medical field, is unclear because of a lack of sufficient, comprehensive nationwide data. France (2005) suggests there is a lack of data to conclusively state whether or not there has been an actual increase in monetary damages rendered in jury cases. Woellert (2005) concurs that this lack of data is in part because there is no central data or reporting for many of the nation's tort verdicts. Since the correlation between liability claims and increased costs is unclear, it is speculation as to whether limited liability through the use of tort caps, as is often proposed, would promote increased production of medical products in general, and vaccines in particular. Admittedly, other countries such as Canada offer alternative models for handling medical malpractice claims which can be studied and their results projected into the United States (Mirmirani et al, 2003). But a detailed study of such projections is beyond the scope of this article.

It is our contention that limiting the liability of vaccine manufacturers alone would not be sufficient to foster increased vaccine production. This statement is based in part on the National Vaccine Injury Compensation Program. Vaccine manufacture is one of the relatively few areas of tort action where there is a procedure already in place a process to protect and limit the liability of manufacturers. The National Childhood Vaccine Injury Act of 1986 (P.L. 99-660) established the National Vaccine Injury Compensation Program. The program is a cooperative effort administered through the U.S. Department of Health and Human Services, the U.S. Court of Federal Claims, and the U.S. Department of Justice. The program itself is located in the Division of Vaccine Injury compensation, Health Resources and Services Administration, Health and Human Services. In effect since October 1, 1988, the program combines elements of traditional litigation with a form of alternate dispute resolution. From a manufacturer's standpoint, the program avoids a jury trial and jury awards, with a cap on damages to be awarded. For instance, in the event of a vaccine related death, the cap is $\$ 250,000$. To be subject to the act's provisions, a vaccine must be listed on the Vaccine Injury Table. There is currently some question as to whether flu vaccines are covered on the table, although it appears the vaccine is now included. On April 12, 2005, the Secretary of Health and Human Services published a notice stating that trivalent influenza vaccines would be covered under the program effective July 1 , 2005. (Health and Human Services 2005)(a). The U.S. Department of Health and Human Services stated on their website that "the ultimate decision" remains with the United States Court of Federal Claims, where the cases under the VICP are heard. (Health and Human Services 2005)(b).

\section{Policy Revisions and Future Prospects}

The unique nature of flu vaccine as a product, the limited time frame of the manufacturing process, and the questionable impact of tort reform, even if allowed, leaves one to ask what can be done to promote production of the vaccine to make the United States self-sufficient and avoid the pitfalls experienced during the 2004-2005 season? Using the basic supply and demand model again, one answer may be to simply create more competition among vaccine manufacturers for the market. Of course, this begs the question as to how to foster competition for a "highrisk, high cost, low-profit" product such as the influenza vaccines. Put another way, what can be done to make the production of flu vaccine financially more viable? The answer suggested herein is a multi-pronged approach which would necessitate government involvement at several levels, including encouraging more efficient production, and reducing the risk elements to suppliers, specifically from tort litigation and from financial losses associated with excessive vaccine production. 
In a free market system, theoretically, an increase in demand would increase price, and that would entice a corresponding increase in production. But as noted above, high production costs, uncertainty of demand, the need for continuous monitoring and research of the changing flu strains and low profit margins all discourage production. The government needs to take a more nationalized, proactive role in encouraging the public to be vaccinated on a yearly basis. This needs to be done not merely by distributing funds to local state health agencies, but by also mounting a national public awareness and information campaign. Such campaign should be sponsored by an appropriate governmental agency at the Federal level, such as the Health Department or the Centers for Disease Control, which already work and would continue to collaborate with state and local heath agencies.

One might think that the recent 2004-2005 shortage could result in more manufacturers seeking to enter the market, viewing a need to be met. It is our contention that the shortage could actually result in reduced vaccine production in coming years. Chiron has asserted their commitment to take "all necessary actions to ensure an adequate vaccine supply for the 2005-2006 influenza season." However, Chiron reported that its 2004 pro forma earnings for the year ending December 31, 2004 were \$133 million, \$0.70 per share, down from \$297 million or \$1.54 per share for 2003. Specifically, Chiron reported a pro forma loss of $\$ 7$ million dollars for the fourth quarter of 2004, which corresponded to suspension of their license to manufacture Fluvirine. Chiron continued to emphasize cooperation with regulatory authorities and a plan to re-enter the flu vaccine market. Chiron's license to produce the flu vaccine was restored by the MHRA on or about March 2, 2005 (FDAnews 2005). But assuming Chiron can meet the demands of regulatory authorities in the United States (specifically the FDA) and England (the MHRA) on a consistent basis, one could certainly speculate as to whether Chiron will pursue the market in light of the hurdles it must face. This is especially of concern when one realizes Chiron made their $\$ 133$ million dollars without any Fluvirin vaccine sales in the third and fourth quarter.

Part of the production cost of almost any product is associated with the risk factors. As noted, when discussing the flu vaccine, two substantial risk factors for the manufacturer include (1) Those associated with tort liability; and (2) the risk of financial loss incurred by the manufacturer due to an overproduction of vaccine in a particular year. Reasonable minds may (and have) differed over the extent that tort liability and fear of tort liability has prompted a decline in domestic production of the flu vaccine. Proponents of tort reform argue that the number of United States-based vaccine manufacturers has dwindled from 12 to 2, and that none of the injectible flu vaccine is domestically produced. It has also been argued that manufacturers are fearful of producing the flu vaccine because, by medical standards, it is given to medically healthy people. The argument goes that if such a person later incurs any injury, "there is a plaintiffs' lawyer waiting in the wings to sue a manufacturer" (American Tort Reform Association 2004). Opponents of tort reform argue that tort reform, and in particular tort caps, have not been conclusively proven to be effective and in fact would deprive injured parties of their rights to justice.

A recent government study on the issue of caps on medical malpractice judgments concluded that there was not enough evidence to conclusively establish whether caps on malpractice awards were effective in reducing malpractice insurance premiums. Further, the apparent noninclusion of the influenza vaccine in the National Vaccines Injury Compensation Program does not afford the manufacturer the limited liability protection afforded by the Program. It is suggested here that the inclusion of the influenza vaccine within the parameters of the National Childhood Vaccine Injury Act is a good preliminary step, and illustrative of the type of government action which will be required. Although still subject to a final declaration from the Court of Federal Claims, this designation should provide limited protection to manufacturers, while still providing a method for persons whose injuries are proximately caused by the flu vaccine to provide prompt and fair compensation.

As for excessive production, this appears to be a problem which can be ameliorated to a degree by public information. As previously noted, CDC's projected needs for the 2004-2005 flu season were 100 million doses of vaccine. But the benefits for the vaccine can be applied to more than that number. There is no need for the yearly destruction of vials when so many people are not vaccinated. What the government must do is to provide financial incentives for the production.

There are a number of ways to offer financial incentives to generate increased vaccine production for sale in the United States. We believe that two methods which would be worth pursuing would be to increase the price paid 
by the government for flu vaccines through the Vaccines for Children Program, and to establish a pilot program whereby the government would guarantee the purchase of surplus vaccine

We do not share the belief of some commentators that the Vaccines for Children Act have driven flu vaccine manufacturers out of the United States market. And, even if we did, we would argue that the health benefits resulting from the act warrant continuation of the program. The Act appears to produce increases vaccination rates among populations which rates would not be as high without the government subsidy. Nevertheless, we recognize that the Act results in the manufacturer selling a large segment of their supply at a price below what could be obtained in a free market. If the government is seeking to encourage more vaccine manufacturing for the United States, it will need to address this price ceiling, perhaps through greater bulk purchases and/or a guarantee to purchase a certain amount of excess or surplus vaccines from the manufacturer. One should know approximately what the financial commitment would be. The Vaccines for Children program served approximately $41 \%$ of the childhood population in 2002, although this figure presumably includes other children's vaccines besides influenza (CDC). The Centers for Disease Control already purchases the vaccine at a reduced price. Negotiating in bulk, the government could still purchase the vaccine at a substantial savings. However, an increase in the price paid would serve as an incentive for greater production among current manufacturers.

An agreement by the government to purchase excess or surplus vaccines from manufacturers would potentially be more costly. Given the fluctuation in demand on a year to year basis, the government could potentially find itself in the market for purchasing thousands if not hundreds of thousands of vials. Politically, this option might also be more difficult for public acceptance as in effect, the government would be subsidizing multinational companies that report yearly profits in the millions (or, in the case of Aventis, in the billions) of dollars. However, it is not unheard of for the government to undertake such subsidy when it is in the best interests of the public to do so. By analogy, the federal government annually invests millions in food subsidies for farmers.

A third area may be in mandating that insurers provide health insurance coverage for flu vaccination. Cain et al (2004) suggest that the availability of insurance and health coverage for out of pocket costs in obtaining a flu shot will greatly influence whether a person will be vaccinated. Such requirements would probably need to be done at the state level, with legislatures mandating that health insurance providers operating in the particular state include such coverage as part of any health plan offered. Clearly, mandating coverage for vaccination shots would be a an additional cost and thus a minor disincentive for some insurers to operate in a state, but government purchases in bulk with resale to health providers could limit these added costs for the insurers.

At the risk of sounding an overly alarmist note, there is a serious potential harm in the foreseeable future which weighs in favor of not only maintaining but increasing both the production and the distribution of flu vaccine. It is our contention that the American public's experience with the 2004-2005 flu vaccine shortage will have an adverse effect on vaccine production for the following flu season. As was widely reported, despite the initial shortage, by February 2005 there were reports of excess flu vaccine. Admittedly, this surplus was almost certainly the result of many persons who otherwise would have obtained the flu vaccine refraining from doing so, as a direct result of CDC requests. However, as the surplus began and the CDC began to loosen its request and encourage more people to seek vaccination, there was not a corresponding increase in vaccination. Seemingly, for many people, once they had made up their mind to not get the vaccine, this mindset stayed and was not changed by the CDC's changes in recommendation. This may have a carry-over effect on the mindset of the American public in the upcoming flu season, the thinking that "I didn't get a flu shot this year and I was fine, why should I get one next year?" Even among high risk groups, a significant number of adults did not seek to obtain the vaccine (Centers for Disease Control 2004)(c). If a vaccine manufacturer believes this is the mindset of the American public, that manufacturer may produce less vaccine and/or invest less in the further production of the vaccine, or potentially leave the market altogether.

Further, through the summer of 2005 a growing number of health care professionals have expressed concern over the avian or so-called "bird" flu. This potentially dangerous flu can be transmitted through contact with infected birds, including but not limited to the consumption of infected poultry, and has a high mortality rate. In Asia it appeared to be transmitted by contact between humans and infected birds, but human to human transmission was 
suspected but not completely confirmed. According to the CDC (2005)(b), as of February 4, 2005, the World Health Organization reported 55 confirmed cases in Asia of the influenza A (H5N1) virus, resulting in 42 deaths.

Some suggest that this avian flu could be the source of the next "pandemic" to strike the world (Business Recorder 2005). In August of 2004 the Department of Health and Human Services produced a draft document to address the potential influenza pandemic, and a proposed response thereto (Health and Human Services 2004)(b). The cost of such a pandemic would far outstrip the normal costs associated with the yearly influenza outbreak. In the same report, DHS states "The ideal pandemic influenza vaccine is one that can be produced in the shortest amount of time, protect the largest number of individuals, and is efficient, safe, and easy to deliver." The actions recommended by the DHS to do this include, but are not limited to, increasing demand for yearly vaccine, providing incentives for manufacturers to enter the U.S. market, and to encourage development of other types of vaccine.

It is impossible to predict with absolute certainty when or whether a variation of the Avian Flu will reach the United States. But undoubtedly, the costs would be prohibitive, both in terms of actual dollars and lives lost. In 1999, Meltzer (1999) estimated the economic costs to the United States of a pandemic to range from $\$ 71.3$ billion to $\$ 107.0$ billion. Meltzer projected that in the event of a pandemic, the influenza virus would result annually in 114,000 hospitalizations, and from between 5 million and 10 million outpatient visits. If private manufacturers determine that low profit margins do not justify continued flu vaccine production and instead direct their production to other more profitable products, the United States will be ill-equipped to respond to an Avian flu pandemic in a timely fashion. Flu vaccine manufacturers and their corresponding production facilities must be in full operation well in advance of such the outbreak. That may require government support of such production facilities, even in those years when the flu appears to be mild.

\section{SUMMARY AND CONCLUSIONS}

Adverse economic repercussions from the 2004-2005 season continue to emerge. On June 15, 2005, Chiron announced that remediation efforts at its factory in Liverpool, England, were continuing. Chiron lowered its projected estimates of the number of does of flu vaccine it would produce for the 2005-2006 season to eighteen (18) to twentysix (26) million doses of Fluvirin, down from its previous projections of between twenty-five (25) to thirty (30) million doses. This also resulted in a reduction in its 2005 earnings forecast (Chiron News, 2005). At almost the same time, Wilkinson (2005), discussing production in the United States and England, reports that some experts predict that economic factors will continue to result in a decrease in the number of private manufacturers producing flu vaccines, suggesting the need for some form of government support (Wilkinson, 2005). However, as noted above, the costs of allowing the decline of the flu manufacturing infrastructure could be enormous. The constantly changing strains of the flu virus necessitate continual vigilance even in so-called "weaker" flu years. As Meltzer suggests, the economic costs of a pandemic, such as the avian bird flu, in the face of a breakdown of the flu production infrastructure system, could indeed be catastrophic. Perhaps the most significant lesson to be learned from reviewing the underlying cause of the 2004-2005 flu vaccine shortage is that the free market alone does not appear to be able to produce profit margins sufficient to support the continued manufacture of vaccines. Reportedly, one of the World Health Organization's flu specialists, Klaus Stoehr, has indicated that the private sector alone cannot produce enough flu vaccine in a sufficient enough time to address an immediate world outbreak of the Avian flu (Business Recorder 2005). A comprehensive list of solutions is beyond the scope of this article, but may include a combination of limited liability, government guarantees to subsidize manufacturer's surplus, relaxed price caps under the Vaccines for Children Program, and an information campaign promoting the need for vaccination. Clearly the need for potentially costly government intervention must be considered in the face of the looming threat of a worldwide pandemic.

\section{REFERENCES}

1. American Tort Reform Association (2004) Flu Vaccine Crisis - Liability is a Cause, Press Release from October 7, 2004, accessed 3/3/05, (available at http://www.atra.org/show/7830 0.

2. Aventis Pasteur (2004) Aventis Pasteur -- U S Influenza Vaccine Supply 2004, Press Release of October 7, 2004. 
3. Bridges, Carolyn B., et al (2000) Effectiveness and Cost-Benefit of Influenza Vaccination of Healthy Working Adults - A Randomized Controlled Trial, The Journal of the American Medical Association, Vol. 284, No. 13, pp. 1655-1663.

4. Business Recorder (2005) Looming Threat of Massive Flu Pandemic, Business Recorder July 29.

5. Cain, Kevin P., and Blitz, Susan g. (2004) Integration of Clinical Practice, Publicity, and Policy: A Shot in the Arm for Influenza, The American Journal of Managed Care, January Issue, pp. 11-12.

6. Cohen, Gail M., and Nettleman, Mary D. (2000) Economic Impact of Influenza Vaccination in Preschool Children, Pediatrics, Vol. 106, No. 5, pp. 973-976.

7. Centers for Disease Control and Prevention and Prevention (2004) (a) Key Facts About the Flu: How to Prevent the Flu and What to Do If you Get Sick, updated November 10, 2004 (available at http://www.cdc.gov/flu/ keyfacts.htm).

8. Center for Disease Control (2004) (b), Updated Interim Influenza Vaccination Recommendations - 2004-2005 Influenza Season. December, 2004. http://www.cdc.gov/flu/protect/whoshouldget.htm (accessed 1/03/05).

9. Center for Disease Control (2004)(c) Experiences with Obtaining Influenza Vaccination Among Person in Priority Groups During a Vaccine Shortage - United States, October -November, 2004, MMRW Weekly, Vol. 53, No. 49, pp. 1153-1155.

10. Centers for Disease Control and Prevention (2005) (a) Key Facts About Influenza and the Influenza Vaccine, updated August 8, 2005 (available at http://www.cdc.gov/flu/keyfacts.htm).

11. Centers for Disease Control and Prevention (2005) (b) Update on Avian Influenza A (H5N1), Influenza (Flu) Protect Yourself \& Your Loved Ones, February 4 (accessed at http://www.cdc.gov/flu/ avian/professional/han020405.htm).

12. Centers for Disease Control and Prevention (2005)(c) 2003-2004 U.S. Influenza Season Summary, Influenza $(F l u)$ - Protect Yourself \& Your Loved Ones (available at http://www.cdc.gov/flu/weekly/weeklyarchives20032004/03-04summary.htm).

13. Chiron Corporation (2005) Chiron Revises Production Range for Fluvirin Vaccine and Updates Financial Guidance; Delays in Reaching Full-Scale Production Expected to Reduce Doses and EPS; Full FDA cGMP Inspection of Liverpool Manufacturing Facility Expected in July, Chiron News, Emeryville; June 15, 2005.

14. FDA News Drug Daily Bulletin (2005) Chiron's Liverpool Plant Gets OK From MHRA, FDA News Drug Daily Bulletin March 10.

15. France, Mike (2005) How to Fix the Tort System, Business Week, March 14, 2005, pp. 70-78

16. Gerberding, Julie L (2004) CDC's Influenza Vaccine Efforts, Testimony before the Committee on Energy and Commerce, U.S. House of Representatives, November 18, 2004 (available at http://www.cdc.gov/washington/ testimony/In11182004209.htm).

17. Health and Human Services (2004)(a) Statement from the Department of Health and Human Services Regarding Chiron Flu Vaccine, News Release, October 5, 2005 (available at http://www.hhs.gov/news/ press/2004pres/20041005.html).

18. Health and Human Services (2004)(b) Draft - Pandemic Influenza Preparedness and Response Plan, Washington, DC, August 2004 (found at http://www.hhs.giv.nvpo/pandemic plan).

19. Health and Human Services, Health Resources and Services Administration, (2005)(a), National Vaccine Injury Compensation Program: Addition of Trivalent Influenza Vaccines to the Vaccine Injury Table, Federal Register, Vol. 70, No. 69, pp. 19092-19093,

20. Health and Human Services, Health Resources and Services Administration, (2005)(b), Influenza Vaccines to be Covered by the VIC, http://www.hrsa.gov/osp/vicp/, (July 8).

21. Hillman, Richard J (2003) Medical Malpractice Insurance - Multiple Factors have Contributed to increased Premium Rates, GAO-03-702, Washington, DC (June 2003).

22. Leinwand, Donna (2004) Experts have been predicting flu vaccine shortage for years, USA Today, October 2, pg $3 \mathrm{~A}$.

23. Marshall, Gary S., M.D. et al. (2004) The Vaccine Handbook: A Practical Guide for Clinicians, Lippincott Williams \& Wilkins, Philadelphia, PA.

24. Meltzer, MI, Cox, NJ, and Fukuda, K. (1999) The economic impact of pandemic influenza in the United States: Priorities for Intervention, Emerging Infect Disease, Vol. 5, No. 5, pp. 659-671.

25. Mirmirani, Sam and Lippmann, Matthias (2003) Medical Malpractice Crisis in the United States: A Case for the Canadian Model, Global Business \& Economics Review - Anthology 2003, pp. 259-269. 
26. National Immunization Program, Centers for Disease Control and Prevention (2004) 2004-2005 Influenza Vaccine Production Update, Influenza Vaccine Bulletin \#3, September 24, 2004 (available at http://www.cdc.gov/nip/flu/bulletin-flu/2004-05/bulletin3).

27. Nichol, K.L., Margolis, K.L., Wuorenma, J., and Von Sternberg, T. (1994) The Efficacy and Cost Effectiveness of Vaccination Against Influenza Among Elderly Persons Living in the Community, The New England Journal of Medicine, Vol. 331, No. 12, pp. 778-784.

28. Niles, Steve (2004) Shot in the arm, Med Ad News, Vol. 23, No. 1, pg. 38.

29. O’Brien, Megan A., et al. (2004) Incidence of Outpatient Visits and Hospitalizations Related to Influenza in Infants and Young Children, Pediatrics, Vol. 113, No. 3, pp. 585-593.

30. Orenstein, Walter, M.D., (2002) Childhood Vaccine Shortage, Federal Document Clearing House Congressional Testimony, remarks before the Senate Committee on Governmental Affairs, June 12, 2002.

31. Sanofi Pasteur (2004) Key facts \& figures in 2003 Facts \& Figures, 2004, accessed 2/23/05, available at http://www.us.aventispasteur.com/index.cfm?FA=FACTS-FIGURES.

32. Senacola, Chris (2004) Shortage causing posturing; Flu shot problems benefit candidates, Worcester Telegram \& Gazette, October 20, 2004.

33. Thaul, Susan (2003) Vaccine Policy Issues for the $108^{\text {th }}$ Congress, Report for Congress, Congressional Research Service, The Library of Congress, updated May 22, 2003.

34. Weissman, Robert (2004) Flu Profiteers, Multinational Monitor, Vol. 25, No. 10, pp. 7-8.

35. Wilkinson, Emma (2005) Crisis in Vaccine Industry Raises Risk of Future Shortages, Pulse, May 21, 1005, pg. 72.

36. Woellert, Lorraine (2005) In This Debate, It's War by Anecdote, Business Week, March 14, 2005, pg. 70. 


\section{NOTES}

